\title{
The Popular Financial Reporting between Theory and Evidence
}

\author{
Paolo Biancone ${ }^{1}$, Silvana Secinaro ${ }^{1}$, Valerio Brescia ${ }^{1} \&$ Daniel Iannaci ${ }^{1}$ \\ ${ }^{1}$ Department of Management, University of Turin, Torino (TO), Italy \\ Correspondence: Valerio Brescia, Department of Management, University of Turin, C.so Unione Sovietica, 218 \\ bis, 10134, Torino (TO), Italy.
}

Received: May 9, 2019

doi:10.5539/ibr.v12n7p45

\begin{abstract}
The main international accounting associations have identified Popular Financial Reporting (PFR) as a decision-making tool to increase accountability and transparency as a possible decision lever coherent with the New Public Governance theory. The study has focused its attention on the features and contents of the PFR identified in the literature and present through the analysis of the 193 PFRs municipalities presented at the PFR Awards Program 2017. The analysis of the presence and absence of some characteristics confirms that the reality does not reflect the theoretical request, moreover the statistical analyzes carried out confirm various hypotheses related to the PFR but reject others such as the criterion of document length. The correlation between socio-economic characteristics of the population and the groupings of characteristics of each PFR. The study confirms a relationship between document length and level of education, and between percentage of non-native English-speaking residents and number of appaerance features. To the 23 observable criteria, additional possible ones are added which, based on logic and empirical evidence, will have to be studied to assess their impact in terms of transparency and accessibility.
\end{abstract}

Keywords: popular financial reporting, transparency, accountability, reporting features, new public governance

\section{Introduction}

\subsection{The New Public Governance and the Popular Financial Reporting}

Approach to New Public Governance (Klijn \& Teisman, 2003; Osborne, 2010; Osborne, Radnor, \& Nasi, 2013) has placed emphasis on the relationship between the stakeholders of reference and the public administration with the introduction of new tools and new levers (Biancone, Secinaro, \& Brescia, 2018a). It becomes urgent to understand and identify the priority stakeholders (Carroll, 1996; Clarkson, 1995; Donaldson \& Preston, 1995) defining the main ones in terms of power, legitimacy and urgency (Mitchell, Agle, \& Wood, 1997). Investors and citizens are the two main stakeholders of interest to public groups. It is emphasized how the reports and disclosures normally realized for a few providers including investors (R. Jones, 1992) supply information which is often too technical and complex to be available and accessible to the citizens (IPSASB, 2014; D. B. Jones, Scott, Kimbro, \& Ingram, 1985). From this perspective, the growing need for accountability towards stakeholders (Bäckstrand, 2006; Belal, 2002; Caperchione, 2003; Collier, 2008; Sternberg, 1997) is a particular feature of the environment of local bodies; the evolution of the concept of citizenship sees him as a user and an active co-producer (Bovaird, 2007; Chess \& Purcell, 1999; Doh \& Guay, 2006) with decision-making power over the business choices made by the local administration. The creation of accessible and transparent financial documents is a starting point for the involvement of citizens, popular financial reporting has gained increasing attention from both scholars, managers and politicians. Several finance professional associations including the Government Finance Officers Association (GFOA), the finance professional association have been promoting the Popular Reporting as a reporting tool. Both the Governmental Accounting Standards Board (GASB) and the Association for Governmental Accountants (AGA) promote the diffusion of popular reporting differently with their own guidelines, also proposing prizes (Harris, McKenzie, \& Rentfro, 2008). Popular Reporting is a communication tool that is placed at the highest level of the "Pyramid of Accountability" prepared by the Association of Government Accountants (AGA), as it can provide aggregated data that meet the needs of public administrations to account about the use of public resources (Association of Government Accountants, 2019). According to GASB the Popular Financial Reporting could be subjected to a comprehensive and easy-going availability of other potential users such as politicians, public sector employees, media, community groups, etc. (Governmental Accounting Standards Board, 1992). Popular Financial Reportings (PFRs) are defined as 
financial reports targeted at public stakeholders (e.g. citizens, businesses and community group) who lack a background in public finance but who need or desire a less detailed overview of the government's financial activities (Yusuf \& Jordan, 2012). The Popular Financial Reporting purpose is to facilitate public stakeholders' understanding of their government's financial activities (Clay \& Olson, 2008). The Government Finance Officers Association (GFOA) as well offers a different approach to the financial statement in generally accepted accounting principles (GAAP). The IPSASB particularly emphasizes that the legislature, which acts in the interests of members of the community, is a major user of Popular Financial Report. Thus, since 2010, according the Conceptual Framework for General Purpose Financial Reporting by Public Sector Entities, the IPSAS identified citizens as primary users of Popular Financial Report. The prospective increase in population requires the identification of tools able to focus the attention on the allocation and use of decreasing resources (Cheshire \& Hay, 2017; Ehrlich \& Holdren, 1971; Fogel \& Costa, 1997; Ladd, 1992; Passel \& D. V. U. S., 2008; Spengler, 2017). The identification of indicators associated with Popular Financial Reporting could allow a better understanding of the correct allocation of resources and outputs at the social level (Biancone \& Secinaro, 2016; Biancone, Secinaro, \& Brescia, 2017c, 2017b, 2018b; Biancone, Secinaro, Brescia, \& Iannaci, 2018; Campra et al., 2019). Starting from the analysis of the literature and research on Popular Financial Reporting it is possible to identify the main necessary elements to increase the structure and contents of the report (Biancone, Secinaro, \& Brescia, 2017a; Cohen \& Karatzimas, 2015; Groff \& Pitman, 2004; Yusuf \& Jordan, 2012; Yusuf, Jordan, Neill, \& Hackbart, 2013). Although the studies conducted do not systematically combine the features present in previous studies. There are not many studies on the subject of Popular Financial Reporting, even though the recognition by supranational bodies and national and international accounting principles of public management. Some were comparing it with other social reporting tools such as Social Reporting and Integrating Reporting denote that the Popular Financial Reporting is the only one with characteristics able to guarantee dissemination by incorporating some elements of the other social reports (Biondi \& Bracci, 2018; Brescia, 2019). The document present since 1990 in the Anglo-Saxon countries and in particular in Canada and America, so much so as to lead to the creation of a prize for its diffusion, could however not comply with what is stated in the literature. Given the lack of capacity and often the distancing of the population of the expressed politics with a low turnout both in America and in Europe, one wonders if the document is well structured and if perhaps at the base there is scarce attention to those who are the criteria for giving citizens real transparency and accountability. Alternatively, the poor reading ability of the socio-demographic characteristics of the reader of the municipalities (Johnston et al., 2019). From what has been previously expressed, a theoretical GAP concerning the clarity of contents that according to the literature, the report must have to be accountable and transparent. The reality also highlights a practical GAP, the prizes provided to the Popular Financial Reporting realized in the American and Canadian cities may not respect the criteria identified with the consequence of not having the desired effect. If the tool has been identified as useful to meet the need of New Public Governance, it is helpful to investigate further. To facilitate the analysis, the Popular Annual Financial Reporting of American and Canadian cities that received an award in the 2017 Program Awards were examined. The study intends:

1) Carry out a brief litterature review identifying all the criteria and the scientific evidences related to the realization of the document to guarantee transparency and accountability.

2) Verify what is actually present among the criteria in the literature in the awarded reports highlighting where new features can be found that are not available in the literature and confirming or denying the existing theory.

The article, through the methodology, better identifies the analyzed sample. The analysis of variables based on the literature review in method provides and define the criteria of the study. The results highlight how observable the literature can be both in quantitative and qualitative terms. Finally, the conclusions highlight useful elements for bridging theoretical and practical GAPs and research questions for the future.

\section{Method}

The 400 Popular Financial Reporting presented at the Popular Annual Financial Reporting Awards Program organized by GFOA (http://www.gfoa.org/2017-results-popular-annual-financial-reporting-award-program) were considered in their initial phase. The presented reports arrive from countries, school districts, municipalities and Public Employees Benefit Systems. The study analyses 193 out of 200 and considers only the Municipality according to most of the reference literature. Seven reports are not available on the official page nor on the institutional ones of the Municipalities. The figure 1 summarizes the phases of the methodology. The GFOA established the Popular Annual Financial Reporting Awards Program (PAFR Program) in 1991 to encourage and assist state and local governments to extract information from their comprehensive annual financial report to produce high quality popular annual financial reports specifically designed to be readily accessible and easily 
understandable to the general public and other interested parties without a background in public finance and then to recognize individual governments that are successful in achieving that goal. American and Canadian cities are therefore an excellent case study from a theoretical point of view because the practice of years has led cities to embrace the instrument. In addition, the municipalities were selected instead of other levels of government because they were closer to the citizen and therefore with a greater relationship between the two subjects with greater capacity to influence accountability (Gaventa \& Valderrama, 1999; Olsson, 2003; Hanberger, 2009).

The analysis was carried out starting from the definition of the variables and characteristics found in the published literature, the identification of the variables within the selected reports, the accounting of the variables present, the categorization of the variables present for groups according to the theory and finally the relationship between more relevant category variables and also demographic characteristics to confirm, add or deny what has been identified to date in the present literature.

The analysis of Popular Annual Financial Reporting Awards Program conducted with a bottom up coding approach by ATLAS software, elaborating grounded and relationships between variables (Bell, Bryman, \& Harley, 2018) allows to identify the elements that best meet the needs of the stakeholders and that must be present in the report (Brescia, 2018). The analysed variables are justified by the Popular Financial Reporting literature aimed at guaranteeing transparency, accountability and proper allocation of resources. The counting of the variables was done directly by the study group on the reports. The presence of each characteristic has been identified and counted, counting it only once when present. The presence of the relationship between variables highlighted in the literature and observable in the chapter is conducted through simple or multivariate linear regression. All statistical analyses were performed using STATA V.13 (Stata Corp, College Station, Texas, USA, 2013) and $\mathrm{p}$ value $<0.05$ was considered significant for all analyses. A robustness test was performed for all analyzes. Since the simple linear correlation is not sufficient, tests of significance of the straight line are also carried out, to verify that the angular coefficient $b$ deviates significantly from zero. The tests used are the t-test, also called Student's t-test, which is based on the comparison between means, and the Fisher's F which is based on the comparison between variances, for which we talk about analysis of variance (Jørgensen, 1983).

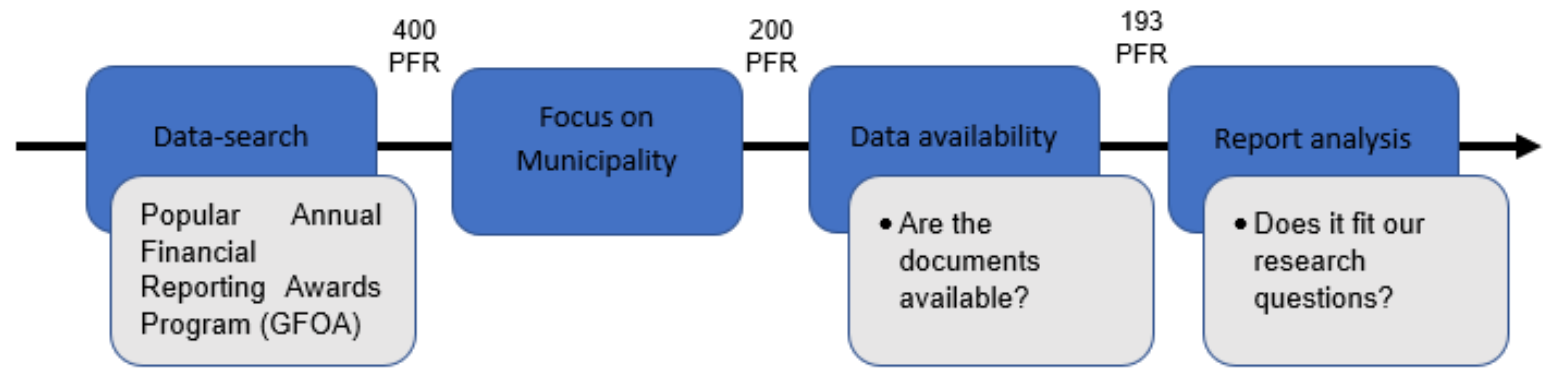

Figure 1. Screening methodology

\subsection{Evidences from the Literature, Variables and Characteristics}

Groff and Pittman (2004) were the first to analyse in 2004 the spread of the popular report as a tool for the dissemination and transparency of public administrations, in accordance with the recommendations of the GFOA'a for using websites to access the government's budgets and financial reporting. They highlight that CAFRs represents a comprehensive and detailed report of all the explanatory elements relating to revenue and public expenditure per service of each city, including quantitative and qualitative elements. Its length varies according to the analysis from 17 to 32 pages. Between 2012 and 2013 Yusuf et al. analysed the essential characteristics and important elements that must be present in the Popular Financial Reporting in the U.S. and Canada context. The Popular Financial Reporting has spread throughout the territory, and even $75 \%$ of public bodies analysed in U.S.A. was using the tool. In Europe, and more precisely in Italy, it will be necessary to wait for the 2014/2015 financial year to have a first case of realization of the document (Biancone et al., 2016). Both the analysed American sample and the Italian one predicts a significant percentage of the population over 65, most of the population is white, most of the population has a high school level. The density of the population, the percentage of people who own a house and the level below the poverty line vary. From the two carried out analyses it is possible to identify two interesting characteristics. Among the percentage of white population and the issue of Popular Financial Reporting in America there is a significant positive correlation $(\mathrm{p}=0.052)$ (Yusuf et al., 2013). The American analysis does not reveal significant aspects between socio-economic factors and analysed results. In Turin a positive linear correlation is identified between the level of education and the reading 
capacity of Popular Financial Reporting ( $\mathrm{p}=0.042)$ (Biancone et al., 2016). Both in the case of the Study of the City of Turin and according to the sample U.S.A. the most involved departments in the realization of the document are the financial and budgeting sectors. Reading the results starting from numerical data provides a greater possibility of identifying the relevance and the "big picture" of the situation. If Yusuf (2012) had identified the most significant criteria for the PFRs to be answered through a first focus group of citizens and a subsequent evaluation of effectiveness by 75 students, in the case of the City of Turin, the second result is based on the indications of a statistically significant percentage of the population (Biancone et al., 2016) on criteria related to the document useful to ensure transparency. Yusuf et al. (2012) identifies and confirms the need for visual aids such as tables, figures and other references to the text, readable spaces and text sizes. The prototype wanted by citizens requires more information on the collection and use of taxes, expenses, economic prospects, including the perspective plan of the city, information on governance, summary of key projects in terms of commitment and use of capital, discussion and description of debt, cost of debt and interest, comparison with the previous year and future perspective, and where possible, a comparison with other cities. The students confirm the highlighted elements adding that the document should not be longer than 7 pages. A specific definition of the efficacy criteria of the PFRs is given. These criteria are largely confirmed by the structure and analysis carried out for the realization of the second European example of Popular Financial Report of the City of Turin for the year 2016/2017. Positive and negative news provide citizens with useful elements to increase credibility and trust in public administration (Anderson \& Edwards, 2015; Clay \& Olson, 2008; Piotrowski \& Van Ryzin, 2007). The PFR in the U.S. context and Canada is used to summarize what was discussed in a discursive manner in the CAFRs with a reference to the less concise document (Groff \& Pitman, 2004). Therefore, if in the Anglo-Saxon context should not exceed 7 pages, in the Italian context a more discursive form of the document is needed. Moreover, from the analyses conducted on the City of Turin, the population appreciates the type of graphs (76.73\%) and tables $(83.86 \%)$ and overall has a high clarity of the provided information $(40.77 \%)$ although it can be further improved $(55.40 \%)$. No differences were found according the level of education (Biancone et al., 2016). Cohen etl al., (2015) proposes the adoption of Integrated Reporting as a tool for representing the six-capital framework as defined by the IIRC $(2013 ; 2014)$ guidelines of the public administration. It proposes the construction of Popular Reporting based on essential information criteria and easy and understandable information for the citizen. This approach aimed at the citizen satisfaction, already includes the elements required for the implementation of Integrated Reporting. The realization of another report, different from the PFRs, is therefore useless, especially in a period of scarcity of available public resources. Precisely the increasing scarcity of resources as well as the perception of the population of inefficiency of municipalities and public bodies in America (ANES, 2019; Yusuf et al., 2013) and the decrease of people involved in elective activities in Italy (Cavallaro, Diamanti, \& Pregliasco, 2018) shift the attention to the need of identifying how resources are actually used. This has led to a greater attention to public management and to the use of resources according to political programs (Ibrahim \& Perez, 2014), costs for providing services (Daniels \& Daniels, 1991), future taxation aspects (Brusca \& Montesinos, 2006), as well as financial condition (Brusca \& Montesinos, 2006). The use of taxes therefore represents a focal point for transparency in the PFRs (Yusuf et al., 2013). If transparency is achieved through a discussion with timely, comprehensible and complete information (Craig, 2004), then the PFR can be a useful tool for analysis. Jordan et al. (2017) has identified 23 criteria useful to create transparent reports from the fiscal point of view the disclosure, starting from what established for the CAFR in U.S.A. and in Canada, based on the criteria already defined by Yusuf et al. (2013) for the realization of the PFRs.

\subsection{The Sample}

The analysed sample includes 193 municipalities, of which 11 are Canadians and the remaining are Americans. The data refer to July 2017. The socio-demographic characteristics of the sample can be viewed in table 1 .

Table 1. Characteristics of the sample

\begin{tabular}{|c|c|c|c|c|}
\hline Variable & Mean & $\begin{array}{l}\text { Std. } \\
\text { Deviation }\end{array}$ & Min & Max \\
\hline Population & 167,02 & $698,339.6$ & 1,270 & $8,622,698$ \\
\hline Population percentage over 65 & 14.84 & 6.71 & 2.8 & 58.8 \\
\hline White alone, percent & 77.49 & 16.91 & 7.6 & 96.8 \\
\hline High school graduate or higher, percent of persons age 25 years+, 2012-2016 & 84.97 & 21.16 & 7.01 & 99.8 \\
\hline Bachelor's degree or higher, percent of persons age 25 years+, 2012-2016 & 38.27 & 16.08 & 9.3 & 78.7 \\
\hline Persons in poverty, percent & 12.35 & 8.10 & 0 & 46.1 \\
\hline $\begin{array}{l}\text { Language other than English spoken at home, percent of persons age } 5 \\
\text { years+, 2012-2016 }\end{array}$ & 20.74 & 19.55 & 1.6 & 96 \\
\hline
\end{tabular}


The municipality with the lowest population is Westlake (TX) while the municipality with the highest population is New York (NY). The city with almost all white population is Powell $(\mathrm{OH})$. The municipality with more high school graded or higher is Topeka $(\mathrm{OH})$ while the one with a lower level is Westlake (TX). The municipality with the highest percentage of the population with bachelor's degree or higher is Topeka (KS) and with less is Seagoville (TX). The city with the highest percentage of people in poverty is Oxford $(\mathrm{OH})$ while the one with a level of 0 is Gilberts (IL). The highest percentage of people who speak a language other than English at home is Frisco (CO) and one in which almost the entire population speaks English as a first language at home is King (NC). The socio-economic considered variables are those considered for the previous analyses identified in the literature on Popular Financial Reporting (Biancone et al., 2016; Yusuf et al., 2013). Statistical analyses conducted between socio-economic variables and characteristics linked to the document always consider the described variables.

\section{Results}

The literature and the conducted analysis identify 48 characteristics divided in 7 groupings: number of pages or length, comprehension, focused community, six capital frameworks, financials, appearance, access. The literature identifies 48 characteristics, but it was not possible to group them all according to the structure already identified by Jordan et al. (2017). In table 2 it is possible to identify the count of each of the characteristics and the possible attribution.

Table 2. Characteristics and groupings of Popular Financial Reporting

\begin{tabular}{|c|c|c|c|c|}
\hline Code & Grounded & Code Groups & $\%$ on total sample & Std. Dev \\
\hline between 51 and 100 pages & 0 & Pages & 0 & 0 \\
\hline Explain acronyms & 0 & COMPREHENSION & 0 & 0 \\
\hline Comics & 1 & & 1 & 0.072 \\
\hline Environmental impact on & 1 & COMMUNITY & & 0.072 \\
\hline performance & & FOCUSED & 1 & \\
\hline Active voice & 2 & COMPREHENSION & 1 & 0.101 \\
\hline Cost of programs or services & 2 & FINANCIALS & 1 & 0.101 \\
\hline over the 100 pages & 2 & Pages & 1 & 0.101 \\
\hline Intellectual Capital & 3 & Six Capital Framework & 2 & 0.124 \\
\hline Television & 5 & & 3 & 0.159 \\
\hline Annual distribution & 6 & ACCESS & 3 & 0.174 \\
\hline between 33 and 50 pages & 6 & Pages & 3 & 0.174 \\
\hline Platform & 7 & & 4 & 0.187 \\
\hline Negative financial outcomes & 11 & FINANCIALS & 6 & 0.232 \\
\hline Human capital & 12 & Six Capital Framework & 6 & 0.242 \\
\hline Infographic & 16 & & 8 & 0.276 \\
\hline Consolidated statements & 17 & & 9 & 0.284 \\
\hline quality of life & 20 & & 10 & 0.030 \\
\hline Natural Capital & 23 & Six Capital Framework & 12 & 0.325 \\
\hline non-financial comparison & 26 & & & 0.342 \\
\hline with previous year & & & 13 & \\
\hline Budget & 40 & & 21 & 0.406 \\
\hline Description of Special or spot & 41 & & & 0.410 \\
\hline project & & & 21 & \\
\hline benchmark context & 43 & & 22 & 0.417 \\
\hline Manufactured Capital & 45 & Six Capital Framework & 23 & 0.424 \\
\hline Social media & 45 & & 23 & 0.424 \\
\hline Non-financial visuals & 56 & APPEARANCE & 29 & 0.455 \\
\hline Overview of financial & 61 & FINANCIALS & & 0.466 \\
\hline condition & & & 32 & \\
\hline between zero and 12 pages & 69 & Pages & 36 & 0.480 \\
\hline Economic trends & 76 & FINANCIALS & 39 & 0.490 \\
\hline \multirow{2}{*}{ Mission statement } & 83 & COMMUNITY & & 0.496 \\
\hline & & FOCUSED & 43 & \\
\hline representation of organization & 96 & & & 0.501 \\
\hline and responsibility & & & 50 & \\
\hline Grants and certifications & 101 & & 52 & 0.501 \\
\hline between 13 pages and 32 & 116 & Pages & & 0.496 \\
\hline pages & & & 60 & \\
\hline Defined Financial terms & 116 & COMPREHENSION & 60 & 0.491 \\
\hline Contact information & 124 & ACCESS & 64 & 0.480 \\
\hline Report overview & 129 & COMPREHENSION & 67 & 0.472 \\
\hline Social Capital & 142 & Six Capital Framework & 74 & 0.442 \\
\hline
\end{tabular}




\begin{tabular}{|c|c|c|c|c|}
\hline Website availability & 142 & ACCESS & 74 & 0.442 \\
\hline Demographic information & 145 & COMMUNITY & & 0.433 \\
\hline $\begin{array}{l}\text { financial comparison with } \\
\text { previous year }\end{array}$ & 155 & & 80 & 0.399 \\
\hline Table of contents & 159 & COMPREHENSION & 82 & 0.382 \\
\hline 10th grade reading level & 163 & COMPREHENSION & 84 & 0.363 \\
\hline Font size & 164 & APPEARANCE & 85 & 0.358 \\
\hline Previous year comparisons & 165 & FINANCIALS & 85 & 0.353 \\
\hline White space & 167 & APPEARANCE & 87 & 0.342 \\
\hline Financial capital & 169 & Six Capital Framework & 88 & 0.330 \\
\hline Charts and graphs & 170 & APPEARANCE & 88 & 0.325 \\
\hline Major taxes and revenues & 173 & FINANCIALS & 90 & 0.306 \\
\hline $\begin{array}{l}\text { Revenue and expenditure } \\
\text { analysis }\end{array}$ & 177 & FINANCIALS & 92 & 0.276 \\
\hline
\end{tabular}

Two characteristics are not attributable to the analysed sample. The first refers to the explanation of each acronym which is not present in the examined reports. The use of acronyms is probably avoided to facilitate the understanding of the document. The other features refer to the length of the reports. Reports of length between 50 and 100 pages are not present. The analysed reports immediately allow to highlight that more than half of the characteristics suggested by the literature are not respected and implemented. Much evidence in the literature has been given to the length of the PFRs. In the sample, reports with a length between 12 and 32 pages (60\% of the sample) and from zero to 12 pages (36\% of the sample) are prevalent. The great importance given to the length of the document must however be evaluated based on the percentage prevalence of characteristics present in the document. Figure 2 shows the carried-out analysis, the groups and the present characteristics.

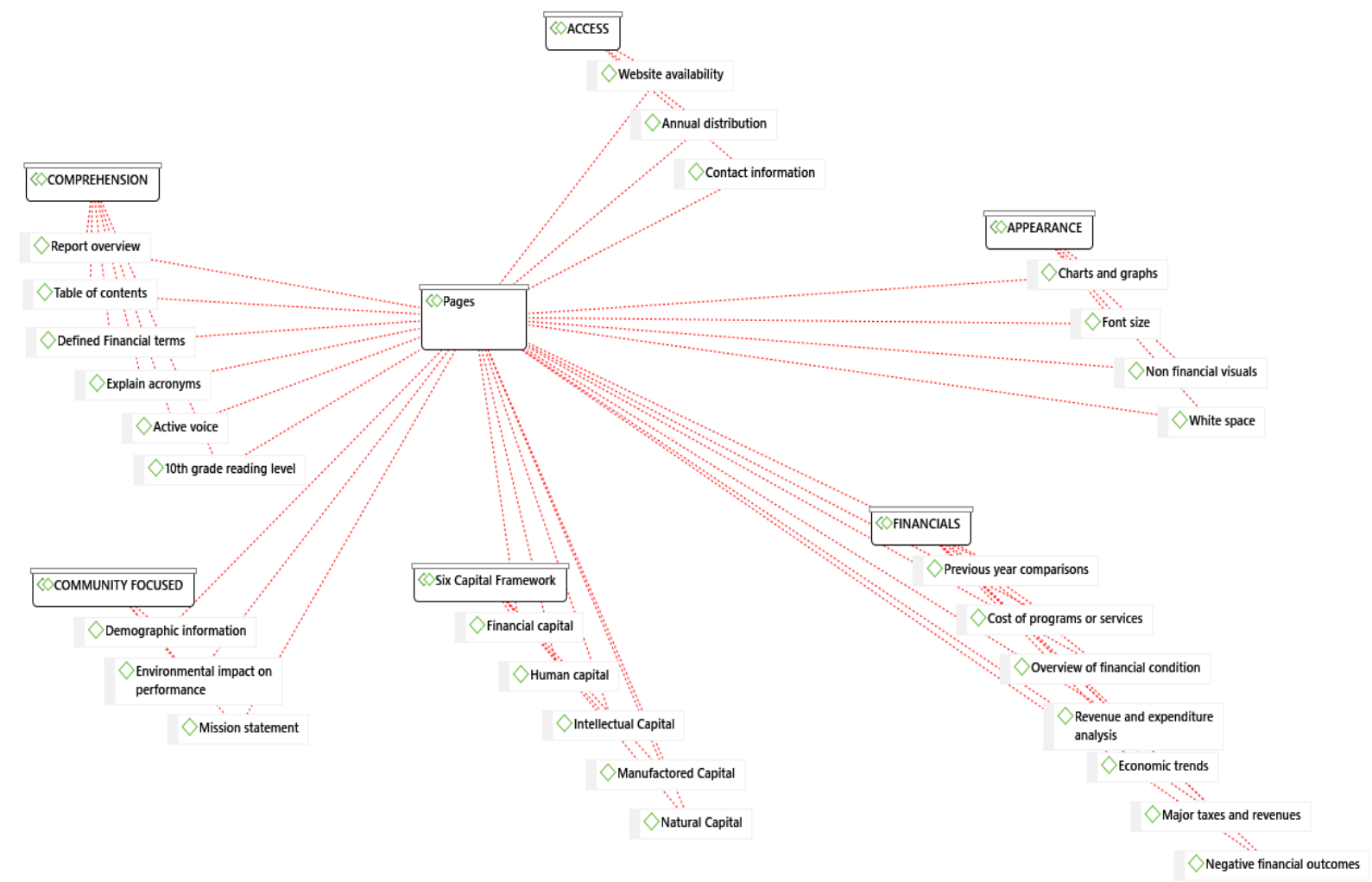

Figure 2. Relationship between number of pages and other characteristics identified in the literature

The average of observable characteristics between 0 and 12 pages is equal to 15.32 , between 13 pages and 32 pages is equal to 12.99 , between 33 pages and 50 is equal to 18.66 and over 100 pages is equal to 16 . The balance between document length and presence of other characteristics must be considered, if the American and Canadian context favours documents with a length not exceeding 32 pages and in many cases from 0 to 12 pages, it is clear that the presence of characteristics undergoes a decrease compared to those present in the most consistent reports. In general, if the groupings of characteristics related to the PFR are analysed, it is possible to highlight a prevalence of the group related to features on financial understanding and understanding of the document as shown in graph 1. 


\section{Characteristics of PFR}
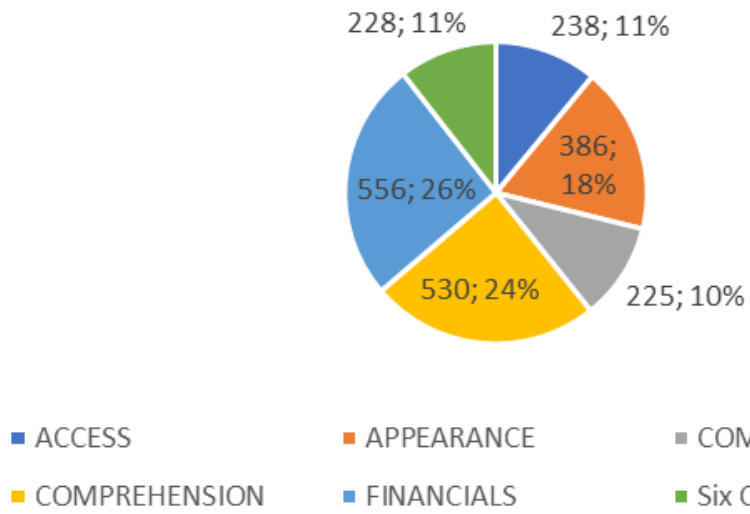

- APPEARANCE

- COMMUNTY FOCUSED

- FINANCIALS

- Six Capital Framework

Graph 1. The characteristics of PFR per group

If the reports are analysed by grouping them by length, it is possible to identify the different representations. Each representation can present the proportionally configured configuration of each cluster by report length Graph 2.

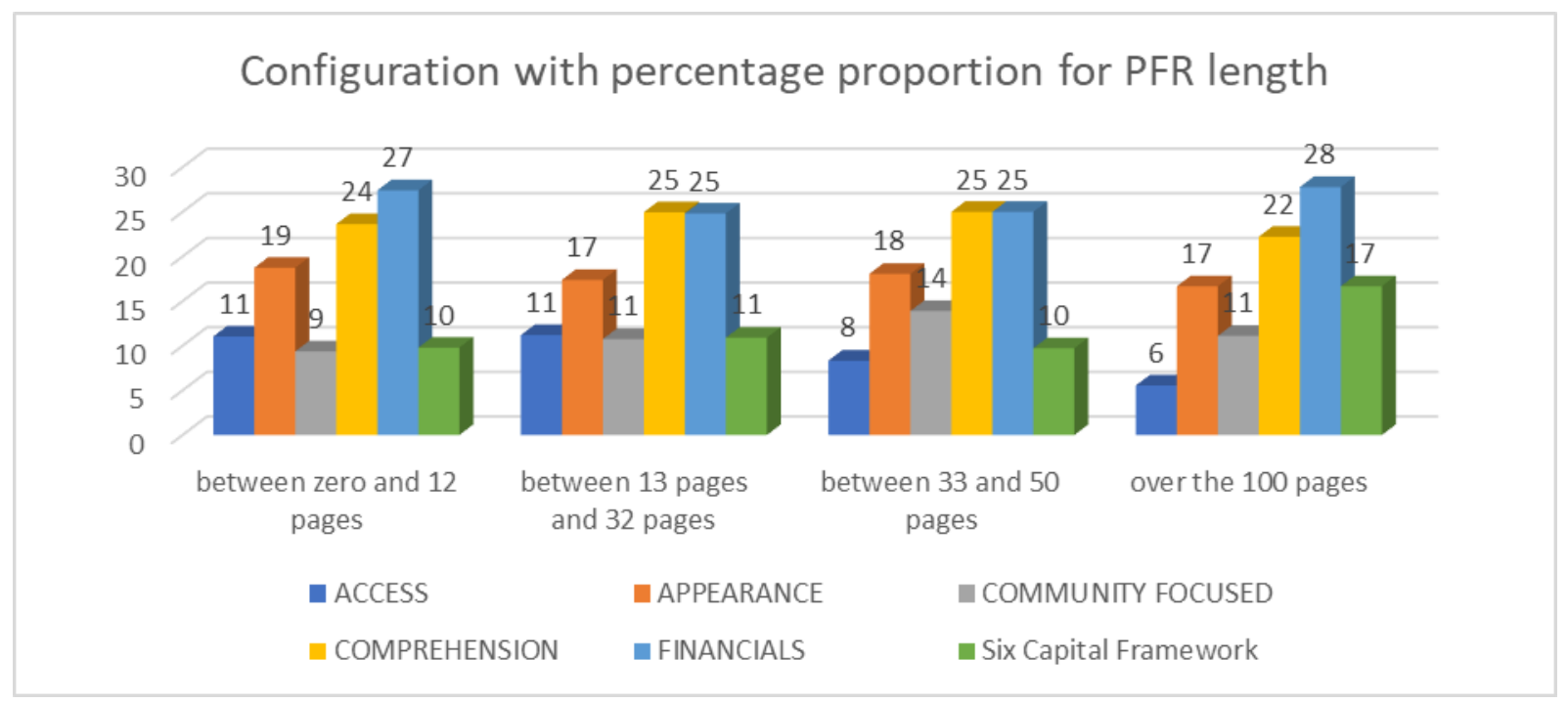

Graph 2. Percentage configuration of the characteristics present in the PFR by grouping

\subsection{Statistical Analysis}

In the literature a lot of evidence is given to the length of the pages of reporting but finding different results like best practice; the analysis will help us to understand what reality is also placing other important analyzes aimed at a deepening of the theoretical approach found.

Comparing the reports based on the length by grouping of characteristics through ANOVA, it should be noted that there is no difference between the different groupings except for criteria related to the representation of the six capital frameworks $\mathrm{p}=0.0284$ and sum of the total totals criteria present in the document $\mathrm{p}=0.0061$.

Through a linear regression, evaluating the relationship between PFR length and PFR grouping characteristics, there is a correlation between number of pages and two groups of characteristics (community focused and six capital frameworks). In the first case, $\mathrm{p}=0.033$ standard error 0.610673 ( $\mathrm{F}$ test $=0.0007$; $\mathrm{t}$ test $=3.46$ ) in the second case $\mathrm{p}=0.014$ with standard error $=0.0646694(\mathrm{~F}$ test $=0.0029, \mathrm{t}$ test $=3.02)$ in both cases $\mathrm{R} 2=0.1008$. There is also a correlation between document length and total number of observable characteristics, as the number of pages increases, the number of characteristics that can be observed $p=0.01$ and $R 2=0.0629$ with 
standard error $=0.0167833$ increases $(F$ test $=0.0004 ; \mathrm{t}$ test $=3.58)$. The multivariate between the length of the reports and socio-economic variables shows that the length of the pages is indirectly proportional to the level of higher education considering the resident population. The number of pages increases when the percentage of residents that have completed the High school decreases $(\mathrm{p}=0.001 \mathrm{R} 2=0.0900$ coef. $-0.00725 ; \mathrm{F}$ test $=0.0002 \mathrm{t}$ test $=-3.75$ ). The relationship between groupings of characteristics and socio-economic indicators does not provide significance for the grouping of features that represent access, community focus, comprehension and financials. The number of characteristics linked to the representation of the six-capital framework is inversely proportional to the percentage of inhabitants who have obtained the upper license. More information on the six capitals is represented as the percentage of inhabitants with the upper license $\mathrm{p}=0.019$ coef. decreases. $-0.0079873 \mathrm{R} 2=0.0612(\mathrm{~F}$ test $=0.0151 ; \mathrm{t}$ test $=-2.45$ ). More information related to the employed and available capital could be used to better understand the allocation of resources and the results of the municipality. Instead, the grouping related to the document's appearance criteria increase with the percentage of residents who do not speak English as the first language $p=0.012$ coef. $0.0067785 \mathrm{R} 2=0.0632(\mathrm{~F}$ test $=0.0066 ; \mathrm{t}$ test $=2.75)$. The clarity of the lengthening becomes essential for the understanding of the document in the graphic sense and of the distribution of contents (tables and graphs, use of white space, font, non-financial visuals).

There are no correlations between the number of awards attributed to the presented PFRs and the characteristics that can be observed in the literature for the construction and contents of the document and not even for the length of the document.

\section{Conclusion and Recommendations}

The study highlights some significant and useful aspects to better define the characteristics necessary to guarantee transparency and accountability towards the population. According to the theory and letterature review, 48 characteristics have been identified, some of them were applied to most of the reports, others are absent. According to the second analysis, the study shows that the length remains an important feature to be assessed in the construction of popular financial reporting as this represents a different configuration of the groupings of average contained characteristics. On a theoretical level the GAP related to the systematization and verification of the literature has been filled giving confirmation of the statistical relationships already detected between socio-demographic characteristics and characteristics of the document, but there are identified additional elements related to those groupings of characteristics of PFR are correlated to the presence of socio-demographic characteristics. However, the different features related to report transparency are not always verified. Moreover, the length is related to the number of information provided on six capitals and on the community focus and deepening of the community. Differently from previous studies, the need to increase the number of pages of the PFR is confirmed when the level of people who have finished high school decreases. There is therefore no fixed number of pages that must be respected to be clear. The grouping of characteristics related to appearance becomes essential when the population has difficulties in understanding the language or does not have a good command of the language used in the municipality. The six-capital framework is important for transparency, so much so that the level of grouping of variables of six capital is closely related to the understanding where the population with a low percentage of residents holds a High school diploma. The study carried out increases and deepens the theoretical knowledge on the characteristics of PFR and rejects some hypotheses previously found in the literature. Moreover, some unclassified elements arise from the analysis and they become useful for a future analysis of the effectiveness of the document and of its possible implementation characteristics. For example, in one case we can find the use of comics to represent information as the use of active items could increase the transparency and accessibility of content. The importance of the dissemination plan is reported in both surveys (Biancone et al., 2016; Yusuf et al., 2013). Public media, local newspapers, newsletters and e-mails become the common means of communication. The official channels remain those to be considered as the most suitable ones for sharing results by the citizens but other useful tools for transparency should not be forgotten. Only in 3 percent of the analysed reports is evidence of diffusion through television, in 4 percent of cases the presence and use of dedicated platforms for accessibility and data analysis provides another useful tool whose effectiveness could be analysed in future studies. There are avant-garde elements already highlighted in the case of the City of Turin, which cannot be found so far in the Canadian and American context, such as the use and insertion of first indicators of quality, the level of social well-being and the analysis of the consolidated municipal group including investee and subsidiaries companies (Brescia, 2019). The difference between reality and the list of characteristics that the instrument must respect according to the literature is evident. There are numerous not applied features. The study therefore also has an impact on the practice, the lack of respect for all the characteristics highlights a possible and consequent lack of transparency and accountability. Moreover, thanks to scientific evidence, it is possible to increase the contents and methods of disseminating the document, making it 
effectively accessible to all. As already pointed out several times by Italian scholars, the document, without being integrated into the e-government process, risks being static and far from the true need linked to full transparency capable of immediately detecting the need for information (Biondi \& Bracci, 2018; Biancone et al., 2018b). The study does not address different aspects that can be explored on the subject of PFR. It has not yet been verified in reality that this group of characteristics has a more significant impact on the ability of reading of the population confirming it in different cities, which means of communication is more appropriate for the diffusion and the practical transposition of the information. No one has ever verified the real relapse and the behavior change of the residents. There are no studies on the costs related to the realization and respect of each characteristic in the realization of the document. No study is present that verifies how the implementation of the PFR also changes the approach within the Public Group and no relapse of the internal perception of the document is provided.

\section{Acknowledgments}

The article was made without financial support. We thank the reviewers of the European Accounting Association for the indications received during the 42nd annual conference 2019 held in Cyprus.

\section{References}

Anderson, D. M., \& Edwards, B. C. (2015). Unfulfilled Promise: Laboratory experiments in public management research. Public Management Review, 17(10), 1518-1542. https://doi.org/10.1080/14719037.2014.943272

ANES. (2019). Electionstudies. Recuperato 29 gennaio 2019, da ANES | American National Election Studies website: https://electionstudies.org/

Association of Government Accountants, A. (2019). AGA - Citizen-Centric Reporting (CCR). Recuperato 29 gennaio 2019, da https://www.agacgfm.org/citizen/

Bäckstrand, K. (2006). Multi-stakeholder partnerships for sustainable development: rethinking legitimacy, accountability and effectiveness. European Environment, 16(5), 290-306. https://doi.org/10.1002/eet.425

Belal, A. R. (2002). Stakeholder accountability or stakeholder management: a review of UK firms' social and ethical accounting, auditing and reporting (SEAAR) practices. Corporate Social Responsibility and Environmental Management, 9(1), 8-25. https://doi.org/10.1002/csr.5

Bell, E., Bryman, A., \& Harley, B. (2018). Business research methods. Oxford university press.

Biancone, P., \& Secinaro, S. (2015). Public Local Group: the financial statement effects of adopting the international public sector accounting standards (The Case of Italy). International Business and Management, 10.

Biancone, P., Secinaro, S., \& Brescia, V. (2016). The Popular Financial Reporting: Focus on Stakeholders-The first European Experience. International Journal of Business and Management, 11(11), 115. https://doi.org/10.5539/ijbm.v11n11p115

Biancone, P., Secinaro, S., \& Brescia, V. (2017a). L'informazione consolidata e gli indicatori Bes: strumenti per una rendicontazione più accessibile ai cittadini. L'esperienza Italiana del Popular Financial. Rivista Italiana di Ragioneria e di Economia Aziendale, 339-354.

Biancone, P., Secinaro, S., \& Brescia, V. (2017b). Popular financial reporting: Results, expense and welfare markers. African Journal of Business Management, 11, 491-501. https://doi.org/10.5897/AJBM2017.8367

Biancone, P., Secinaro, S., \& Brescia, V. (2017c). The Popular Financial Reporting and Gender Accountability, the Integrated Approach in Municipalities and Public Bodies. American International Journal of Contemporary Research, 7, 1-11. https://doi.org/10.5539/ijbm.v11n11p115

Biancone, P., Secinaro, S., \& Brescia, V. (2018a). A Review of Big Data Quality and an Assessment Method and features of Data Quality for Public Health Information Systems. International Journal of Management Sciences and Business Research, 7(1), 19-33.

Biancone, P. P., Secinaro, S., \& Brescia, V. (2018). The innovation of local public-sector companies: Processing big data for transparency and accountability. African Journal of Business Management, 12(15), 486-500. https://doi.org/10.5897/AJBM2018.8596

Biancone, P., Secinaro, S., \& Brescia, V. (2018b). Better Life Index and Health Care Quality Indicators, Two New Instruments to Evaluate the Healthcare System. International Journal of Business and Management, 13(2), 29-39. https://doi.org/10.5539/ijbm.v13n2p29 
Biancone, P., Secinaro, S., Brescia, V., \& Iannaci, D. (2018). The Popular Financial Reporting as tool to measure social impact. Presentato al 14TH INTERDICIPLINARY CONFERENCE ON INTANGIBLES AND INTELLECTUAL CAPITAL, Munich.

Biondi, L., \& Bracci, E. (2018). Sustainability, Popular and Integrated Reporting in the Public Sector: A Fad and Fashion Perspective. Sustainability, 10(9), 3112. https://doi.org/10.3390/su10093112

Bovaird, T. (2007). Beyond Engagement and Participation: User and Community Coproduction of Public Services. Public Administration Review, 67(5), 846-860. https://doi.org/10.1111/j.1540-6210.2007.00773.x

Brescia, V. (2019). The popular financial reporting: new accounting tool for Italian municipalities. FrancoAngeli.

Brescia V. (2018). The futures of 193 Popular Financial Reporting of Awards Program 2017 and social economic elements [Data set]. Zenodo.

Brusca, I., \& Montesinos, V. (2006). Are citizens significant users of government financial information? Public Money and Management, 26(4), 205-209. https://doi.org/10.1111/j.1467-9302.2006.00526.x

Campra, M., Secinaro, S., Brescia, V., \& Gonçalves Góis, C. (2019). Redefining the New Public Management and Effects of Indicators: Sustainable Healthcare Mobility. Journal of Management and Sustainability, 9(1), 141-158. https://doi.org/10.5539/jms.v9n1p141

Caperchione, E. (2003). Local government accounting system reform in Italy: a critical analysis. Journal of Public Budgeting, Accounting \& Financial Management, 15(1), 110-145. https://doi.org/10.1108/JPBAFM-15-01-2003-B007

Carroll, A. B. (1996). Business and Society-Ethics and Stakeholder Management. Cincinnati: South-Western Publishing Co.

Cavallaro, M., Diamanti, G., \& Pregliasco, L. (2018). Una nuova Italia: Dalla comunicazione ai risultati, un'analisi delle elezioni del 4 marzo. LIT EDIZIONI.

Cheshire, P. C., \& Hay, D. G. (2017). Urban Problems in Western Europe: an economic analysis. Routledge. https://doi.org/10.4324/9781315100203

Chess, C., \& Purcell, K. (1999). Public participation and the environment: Do we know what works? ACS Publications. https://doi.org/10.1021/es980500g

Clarkson, M. E. (1995). A stakeholder framework for analyzing and evaluating corporate social performance. Academy of Management Review, 20(1), 92-117. https://doi.org/10.5465/amr.1995.9503271994

Clay, P. M., \& Olson, J. (2008). Defining" fishing communities": vulnerability and the Magnuson-Stevens fishery conservation and management act. Human Ecology Review, 143-160.

Cohen, S., \& Karatzimas, S. (2015). Tracing the future of reporting in the public sector: introducing integrated popular reporting. International Journal of Public Sector Management, 28(6), 449-460. https://doi.org/10.1108/IJPSM-11-2014-0140

Collier, P. M. (2008). Stakeholder accountability: A field study of the implementation of a governance improvement plan. Accounting, Auditing \& Accountability Journal, 21(7), 933-954. https://doi.org/10.1108/09513570810907429

Craig, S. C. (2004). Rehabilitation versus Control: An Organizational Theory of Prison Management. The Prison Journal, 84(4_suppl), 92S-114S. https://doi.org/10.1177/0032885504269394

Daniels, J. D., \& Daniels, C. E. (1991). Municipal financial reports: What users want. Journal of Accounting and Public Policy, 10(1), 15-38. https://doi.org/10.1016/0278-4254(91)90018-F

Doh, J. P., \& Guay, T. R. (2006). Corporate social responsibility, public policy, and NGO activism in Europe and the United States: An institutional-stakeholder perspective. Journal of Management Studies, 43(1), 47-73. https://doi.org/10.1111/j.1467-6486.2006.00582.x

Donaldson, T., \& Preston, L. E. (1995). The stakeholder theory of the corporation: Concepts, evidence, and implications. Academy of Management Review, 20(1), 65-91. https://doi.org/10.5465/amr.1995.9503271992

Ehrlich, P. R., \& Holdren, J. P. (1971). Impact of population growth. Science, 171(3977), 1212-1217. https://doi.org/10.1126/science.171.3977.1212

Fogel, R. W., \& Costa, D. L. (1997). A theory of technophysio evolution, with some implications for forecasting population, health care costs, and pension costs. Demography, 34(1), 49-66. 
https://doi.org/10.2307/2061659

Gaventa, J., \& Valderrama, C. (1999, June). Participation, citizenship and local governance. In Background note for the workshop "Strengthening Participation in Local Governance," University of Sussex, Institute of Development Studies (Vol. 21).

Governmental Accounting Standards Board, (GASB). (1992). GASB Technical Bulletin (N. 92-1).

Groff, J. E., \& Pitman, M. K. (2004). Municipal financial reporting on the world wide web: a survey of financial data displayed on the official websites of the 100 largest US municipalities. The Journal of Government Financial Management, 53(2), 20.

Hanberger, A. (2009). Democratic Accountability in Decentralised Governance 1. Scandinavian Political Studies, 32(1), 1-22. https://doi.org/10.1111/j.1467-9477.2008.00220.x

Harris, J., McKenzie, K., \& Rentfro, R. (2008). Efforts and Accomplishments in Communicating Efforts and Accomplishments in Communicating with the Citizenry. Journal of Government Financial Management, 57(3).

Ibrahim, M. E., \& Perez, A. O. (2014). Effects of organizational justice, employee satisfaction, and gender on employees' commitment: evidence from the UAE. Vldots Journal of Business and Management. https://doi.org/10.5539/ijbm.v9n2p45

IPSASB, J. (2014). The conceptual framework for general purpose financial reporting by public sector entities.

Johnston, R., Rohla, R., Manley, D., \& Jones, K. (2019). Voting for Trump and the electoral mosaics of US metropolitan areas: Exploring changing patterns of party support by neighborhood. Cities, 86, 94-101. https://doi.org/10.1016/j.cities.2018.12.011

Jones, D. B., Scott, R. B., Kimbro, L., \& Ingram, R. W. (1985). The needs of users of governmental financial reports. Governmental Accounting Standards Board of the Financial Accounting Foundation.

Jones, R. (1992). The development of conceptual frameworks of accounting for the public sector. Financial Accountability \& Management, 8(4), 249-264. https://doi.org/10.1111/j.1468-0408.1992.tb00442.x

Jordan, M. M., Yusuf, J. E., Berman, M., \& Gilchrist, C. (2017). Popular Financial Reports as Fiscal Transparency Mechanisms: An Assessment Using the Fiscal Transparency Index for the Citizen User. International Journal of Public Administration, 40(8), 625-636. https://doi.org/10.1080/01900692.2016.1186175

Jørgensen, B. (1983). Maximum likelihood estimation and large-sample inference for generalized linear and nonlinear regression models. Biometrika, 70(1), 19-28. https://doi.org/10.1093/biomet/70.1.19

Klijn, E. H., \& Teisman, G. R. (2003). Institutional and Strategic Barriers to Public —Private Partnership: An Analysis of Dutch Cases. Public Money \& Management, 23(3), 137-146. https://doi.org/10.1111/1467-9302.00361

Ladd, H. F. (1992). Population Growth, Density and the Costs of Providing Public Services. Urban Studies, 29(2), 273-295. https://doi.org/10.1080/00420989220080321

Mitchell, R. K., Agle, B. R., \& Wood, D. J. (1997). Toward a theory of stakeholder identification and salience: defining the principle of who and what really counts. Academy of Management Review, 22(4), 853-886. https://doi.org/10.5465/AMR.1997.9711022105

Olsson, J. (2003). Democracy paradoxes in multi-level governance: theorizing on structural fund system research. Journal of European Public Policy, 10(2), 283-300. https://doi.org/10.1080/1350176032000059044

Osborne, S. P. (2010). Delivering Public Services: Time for a new theory? Public Management Review, 12(1), 1-10. https://doi.org/10.1080/14719030903495232

Osborne, S. P., Radnor, Z., \& Nasi, G. (2013). A New Theory for Public Service Management? Toward a (Public) Service-Dominant Approach. The American Review of Public Administration, 43(2), 135-158. https://doi.org/10.1177/0275074012466935

Passel, J. S., \& D. V. U. S., C. (2008). U.S. population projections: 2005-2050. Pew Research Center.

Piotrowski, S. J., \& Van Ryzin, G. G. (2007). Citizen Attitudes Toward Transparency in Local Government. The American Review of Public Administration, 37(3), 306-323. https://doi.org/10.1177/0275074006296777

Spengler, J. J. (2017, luglio 5). Population and Economic Growth. https://doi.org/10.4324/9781315127002-5 
Sternberg, E. (1997). The Defects of Stakeholder Theory. Corporate Governance: An International Review, 5(1), 3-10. https://doi.org/10.1111/1467-8683.00034

Yusuf, J. E., \& Jordan, M. M. (2012). Effective popular financial reports: The citizen perspective. Journal of Government Financial Management, 61(4).

Yusuf, J. E., Jordan, M. M., Neill, K. A., \& Hackbart, M. (2013). For the people: Popular financial reporting practices of local governments. Public Budgeting \& Finance, 33(1), 95-113.

https://doi.org/10.1111/j.1540-5850.2013.12003.x

\section{Copyrights}

Copyright for this article is retained by the author(s), with first publication rights granted to the journal.

This is an open-access article distributed under the terms and conditions of the Creative Commons Attribution license (http://creativecommons.org/licenses/by/4.0/). 